\title{
Myocardial perfusion imaging prior to coronary revascularization: From risk stratification to procedure guidance
}

\author{
Patrick Proctor, $M D,{ }^{a, b}$ Firas Al Solaiman, $M D,{ }^{a, b}$ and Fadi G. Hage, $M D$, \\ FASNC $^{\mathrm{a}, \mathrm{b}}$ \\ a Division of Cardiovascular Disease, Department of Medicine, University of Alabama at \\ Birmingham, Birmingham, AL \\ b Section of Cardiology, Birmingham Veterans Affairs Medical Center, Birmingham, AL
}

Received Dec 4, 2017; accepted Dec 5, 2017

doi: $10.1007 / \mathrm{s} 12350-018-1221-\mathrm{z}$

\section{See related article, pp. 944-953}

According to the 2016 American Heart Association Heart Disease and Stroke statistics update, 16.5 million people in the United States $\geq 20$ years of age have coronary artery disease (CAD). ${ }^{1}$ A large study of all veterans undergoing elective coronary angiography in the Veterans Affairs health care system between 2007 and 2012 demonstrated that the 1-year risk of death or myocardial infarction for patients with obstructive CAD ranges from twice (for 1-vessel disease) to more than quadruple (for 3-vessel or left main disease) that of patients without visible CAD. ${ }^{2}$ Furthermore, obstructive $\mathrm{CAD}$ is a frequent cause of angina which may limit quality of life. ${ }^{3}$ In patients with stable CAD, coronary revascularization may be pursued to (1) decrease angina and improve quality of life, and/or (2) to prolong life and prevent downstream hard cardiovascular events such as myocardial infarction. The role of coronary revascularization in patients with obstructive but stable CAD, and how best to perform it, is a topic of ongoing debate and research.

Large clinical trials have conclusively shown that both optimal medical therapy and revascularization can achieve improvement in myocardial ischemic burden, as

Reprint requests: Patrick Proctor, MD, Division of Cardiovascular Disease, Department of Medicine, University of Alabama at Birmingham, 306 Lyons-Harrison Research Building, 701 19th Street South, Birmingham, AL 35294-0007; proctor@uab.edu J Nucl Cardiol 2019;26:954-7.

$1071-3581 / \$ 34.00$

Copyright (C) 2018 American Society of Nuclear Cardiology. assessed by myocardial perfusion imaging (MPI), and symptom burden. ${ }^{4-7}$ For example, in the Clinical Outcomes Utilizing Revascularization and Aggressive Drug Evaluation (COURAGE) trial, both the PCI and medical therapy groups experienced an approximately sixfold reduction in angina prevalence, with $74 \%$ of the PCI group and $72 \%$ of the medical therapy group free of angina at 5-year follow-up. A substudy of COURAGE using nuclear myocardial perfusion stress testing revealed that patients in both arms also exhibited improvement in myocardial perfusion; at a mean followup of 12 months, at least $5 \%$ absolute reduction in ischemic myocardium was seen in $33 \%$ of patients in PCI group and $19 \%$ of patients in medical therapy group. Another substudy of COURAGE used the Seattle Angina Questionnaire to evaluate five domains of patient-reported health status, including physical limitation, angina frequency, and quality of life, over 3 years of follow-up after randomization. A clinically significant improvement in each of these measures at 3 years was seen in a large proportion of patients with no significant difference between the two arms. ${ }^{9}$ The recently presented Objective Randomised Blinded Investigation with optimal medical Therapy of Angioplasty in stable angina (ORBITA) trial cast some doubt on the effectiveness of PCI on symptom burden in stable CAD when assessed in a blinded, randomized placebo-controlled fashion. ${ }^{10}$ There is abundance of literature on the prognostic value of MPI in patients with stable CAD which allows for its use in risk stratification. $^{11-13}$ While the COURAGE trial did not demonstrate a benefit of coronary revascularization on hard cardiovascular events in patients with stable CAD, ${ }^{5}$ a seminal retrospective study suggested that MPI may be useful to guide coronary revascularization. ${ }^{14}$ In that study, patients with moderate or severe ischemia had 
lower cardiac death with revascularization while those with no or mild ischemia did better with medical therapy without revascularization. These data have been reproduced in multiple independent retrospective studies ${ }^{15-17}$ but not in all. ${ }^{18}$ It is important to emphasize that we still lack prospective studies validating the role of MPI in guiding coronary revascularization.

An important question in clinical management of patients with stable CAD is whether a non-invasive technique can reliably predict improvement in blood flow and ischemia to a specific region of myocardium after revascularization. Bober et al. ${ }^{19}$ used positron emission tomography (PET) stress testing before and after coronary revascularization in a small series of 19 patients to show that myocardial regions with perfusion defects on initial imaging achieved a significant improvement in blood flow after revascularization. The study was not powered to detect differences in clinical outcomes, but the data suggest that MPI may be useful for determining if a myocardial region will or will not benefit from revascularization. A logical next step would be to evaluate whether patients with ischemia on MPI who receive revascularization of the specific ischemic territory have better clinical outcomes than those who do not, either because the revascularization failed to include all of the ischemic territory, or no intervention was performed at all.

In this issue of the Journal, Li et al. ${ }^{20}$ report on a retrospective study of 286 consecutive patients who underwent stress and rest SPECT MPI prior to treatment by complete coronary revascularization (CCR), incomplete coronary revascularization (ICR), or no coronary revascularization (NCR) within 3 months of MPI. All patients had significant CAD by angiography defined as $\geq 70 \%$ diameter stenosis of at least one major epicardial artery or one of its major branches. Uniquely, the completeness of coronary revascularization was defined by ischemia on MPI rather than by anatomic obstruction on angiography ${ }^{21}$-i.e., if a patient had ischemia in the LAD territory and significant stenoses in both the LAD and LCX territories, revascularization of the LAD lesion alone would suffice to consider this CCR. Conversely, if the same patient had only LCX stenosis that underwent revascularization but an $\mathrm{LAD}$ that had diffuse disease not amenable to revascularization, it would be considered ICR. The aim of the study was to compare the outcomes of each treatment group and determine how those outcomes differ between patients with vs without moderate-severe baseline ischemia. Among all patients over a mean follow-up of 46 months, there were 30 deaths and 65 major adverse cardiovascular events (MACE-defined as all-cause death, non-fatal myocardial infarction, or unplanned repeat revascularization).
In this study, $39 \%$ of patients received CCR, $32 \%$ ICR, and 29\% NCR. Coronary revascularization (CCR and ICR combine) was associated with lower MACE $(22.1 \%$ vs $36.4 \%, P<.001)$ but similar mortality (15.5\% vs $15.5 \%, P=.163$ ) compared to NCR. CCR was associated with significantly lower mortality and MACE in both the overall cohort (death HR 1.88, $P=.018$; MACE HR 2.10, $P<.001$ as compared to ICR/NCR) and among patients with $\geq 10 \%$ ischemic myocardium on baseline MPI (death HR 1.71, $P=.017$; MACE HR 2.08, $P<.001$ as compared to ICR/NCR), but not among those with less ischemia. In multivariate Cox regression, CCR was independently associated with lower mortality (hazard ratio $0.31, P=.017$ ) and MACE (hazard ratio $0.30, P<.001$ ). The authors conclude that CCR is associated with superior outcomes compared with ICR or NCR in patients with obstructive CAD and detectable ischemia on MPI, especially in patients with $\geq 10 \%$ ischemic myocardium.

One very important aspect of the present study is the use of MPI, rather than coronary angiography, for defining complete and incomplete revascularization. As the authors point out in their discussion, revascularization is often incomplete even when done in the controlled setting of clinical trials. For example, in the COURAGE nuclear substudy, nearly half of patients had $\geq 5 \%$ ischemic myocardium after PCI, and $16 \%$ had $\geq 10 \%$ ischemic myocardium. ${ }^{8}$ A key limitation is the absence of follow-up imaging to determine the effect of revascularization and/or medical therapy on the perfusion abnormality. We are therefore uncertain whether revascularization, even if complete by this definition, resulted in resolution of ischemia. By the same token, it is possible that ICR or even NCR may have resulted in comparable favorable effects on myocardial perfusion. ${ }^{22}$ Nevertheless, prior studies using serial MPI have demonstrated that coronary revascularization is more effective at reducing myocardial ischemia than medical therapy, ${ }^{7,8,23,24}$ and that changes in myocardial perfusion on serial imaging provide useful prognostic information that associates with cardiovascular events even after accounting for baseline perfusion defect size, left ventricular ejection fraction, and clinical characteristics. ${ }^{25}$ In the study by El-Hajj et al. ${ }^{25}$ of 698 patients who underwent serial regadenoson MPI, the worst outcomes were seen in patients who had worsening perfusion pattern over time irrespective of whether or not they had coronary revascularization in the interim. Another limitation involves the determination of coronary territories by myocardial perfusion which is not an exact science and may be misleading on occasions due to the wellknown overlap of these territories. This may have led to misclassification of the completeness of 
revascularization. An important limitation in this study, similar to any other retrospective study, is that the decision for coronary revascularization and its completeness is not randomized and therefore may have been due to a number of characteristics that were not accounted for, and these in turn may have affected the clinical outcome. The small sample size and the relatively small number of events during follow-up are other limitations. Finally, in the ICR arm it is unclear whether CCR was feasible but not performed or not feasible at all, and therefore could not have been performed.

The study by Li et al. ${ }^{20}$ adds to the literature on how MPI can be used to guide management of patients with stable CAD and help in the decision making of when coronary revascularization is useful. The ongoing International Study of Comparative Health Effectiveness with Medical and Invasive Approaches (ISCHEMIA) trial will provide prospective randomized controlled data on this subject in the near future. ${ }^{26}$ It is certain that MPI has a key role in the management of patients with stable CAD at every level from diagnosis, to risk stratification, and ultimately to decision making.

\section{Disclosures}

Dr. Hage has received research grants support from Astellas Pharma. Dr. Proctor and Dr. Al Solaiman have no disclosure relevant to this publication.

\section{References}

1. Benjamin EJ, Blaha MJ, Chiuve SE, Cushman M, Das SR, Deo R, et al. Heart disease and stroke statistics-2017 update: A Report from the American Heart Association. Circulation 2017;135:e146603.

2. Maddox TM, Stanislawski MA, Grunwald GK, Bradley SM, Ho PM, Tsai TT, et al. Nonobstructive coronary artery disease and risk of myocardial infarction. JAMA 2014;312:1754-63.

3. Steg PG, Greenlaw N, Tendera M, Tardif JC, Ferrari R, Al-Zaibag $\mathrm{M}$, et al. Prevalence of anginal symptoms and myocardial ischemia and their effect on clinical outcomes in outpatients with stable coronary artery disease: Data from the International Observational CLARIFY Registry. JAMA Intern Med 2014;174:1651-9.

4. Group BDS, Frye RL, August P, Brooks MM, Hardison RM, Kelsey SF, et al. A randomized trial of therapies for type 2 diabetes and coronary artery disease. N Engl J Med 2009;360:250315 .

5. Boden WE, O'Rourke RA, Teo KK, Hartigan PM, Maron DJ, Kostuk WJ, et al. Optimal medical therapy with or without PCI for stable coronary disease. N Engl J Med 2007;356:1503-16.

6. Mahmarian JJ, Dakik HA, Filipchuk NG, Shaw LJ, Iskander SS, Ruddy TD, et al. An initial strategy of intensive medical therapy is comparable to that of coronary revascularization for suppression of scintigraphic ischemia in high-risk but stable survivors of acute myocardial infarction. J Am Coll Cardiol 2006;48:2458-67.
7. Nudi F, Di Belardino N, Versaci F, Pinto A, Procaccini E, Neri G, et al. Impact of coronary revascularization vs medical therapy on ischemia among stable patients with or suspected coronary artery disease undergoing serial myocardial perfusion scintigraphy. J Nucl Cardiol 2016. https://doi.org/10.1007/s12350-016-0504-5.

8. Shaw LJ, Berman DS, Maron DJ, Mancini GB, Hayes SW, Hartigan PM, et al. Optimal medical therapy with or without percutaneous coronary intervention to reduce ischemic burden: results from the clinical outcomes utilizing revascularization and aggressive drug evaluation (COURAGE) trial nuclear substudy. Circulation 2008;117:1283-91.

9. Weintraub WS, Spertus JA, Kolm P, Maron DJ, Zhang Z, Jurkovitz $\mathrm{C}$, et al. Effect of PCI on quality of life in patients with stable coronary disease. N Engl J Med 2008;359:677-87.

10. Al-Lamee R, Thompson D, Dehbi HM, Sen S, Tang K, Davies J, et al. Percutaneous coronary intervention in stable angina (ORBITA): a double-blind, randomised controlled trial. Lancet 2017. https://doi.org/10.1016/S0140-6736(17)32714-9.

11. Shaw LJ, Hage FG, Berman DS, Hachamovitch R, Iskandrian A. Prognosis in the era of comparative effectiveness research: where is nuclear cardiology now and where should it be? J Nucl Cardiol 2012;19:1026-43.

12. Hage FG, Ghimire G, Lester D, McKay J, Bleich S, El-Hajj S, et al. The prognostic value of regadenoson myocardial perfusion imaging. J Nucl Cardiol 2015;22:1214-21.

13. Cantoni V, Green R, Acampa W, Petretta M, Bonaduce D, Salvatore $\mathrm{M}$, et al. Long-term prognostic value of stress myocardial perfusion imaging and coronary computed tomography angiography: A meta-analysis. J Nucl Cardiol 2016;23:185-97.

14. Hachamovitch R, Hayes SW, Friedman JD, Cohen I, Berman DS. Comparison of the short-term survival benefit associated with revascularization compared with medical therapy in patients with no prior coronary artery disease undergoing stress myocardial perfusion single photon emission computed tomography. Circulation 2003;107:2900-7.

15. Moroi M, Yamashina A, Tsukamoto K, Nishimura T, Investigators JA. Coronary revascularization does not decrease cardiac events in patients with stable ischemic heart disease but might do in those who showed moderate to severe ischemia. Int J Cardiol 2012;158: 246-52.

16. Boiten HJ, van den Berge JC, Valkema R, van Domburg RT, Zijlstra F, Schinkel AF. Ischemia burden on stress SPECT MPI predicts long-term outcomes after revascularization in stable coronary artery disease. J Nucl Cardiol 2016. https://doi.org/ 10.1007/s12350-016-0735-5.

17. Sorajja P, Chareonthaitawee P, Rajagopalan N, Miller TD, Frye RL, Hodge DO, et al. Improved survival in asymptomatic diabetic patients with high-risk SPECT imaging treated with coronary artery bypass grafting. Circulation 2005;112:I311-6.

18. Shaw LJ, Weintraub WS, Maron DJ, Hartigan PM, Hachamovitch $\mathrm{R}$, Min JK, et al. Baseline stress myocardial perfusion imaging results and outcomes in patients with stable ischemic heart disease randomized to optimal medical therapy with or without percutaneous coronary intervention. Am Heart J 2012;164:243-50.

19. Bober RM, Thompson CD, Morin DP. The effect of coronary revascularization on regional myocardial blood flow as assessed by stress positron emission tomography. J Nucl Cardiol 2017;24:96174.

20. Li J, Yang X, Tian Y, Wei H, Hacker M, Li X, et al. Complete revascularization determined by myocardial perfusion imaging could improve the outcomes of patients with stable coronary artery disease, compared with incomplete revascularization and no revascularization. J Nucl Cardiol 2017. https://doi.org/10.1007/ s12350-017-1145-z. 
21. Li J, Schindler TH, Qiao S, Wei H, Tian Y, Wang W, et al. Impact of incomplete revascularization of coronary artery disease on longterm cardiac outcomes. Retrospective comparison of angiographic and myocardial perfusion imaging criteria for completeness. J Nucl Cardiol 2016;23:546-55.

22. Farag AA, Hage FG. Medical therapy for the treatment of myocardial ischemia. J Nucl Cardiol 2016;23:837-9.

23. Mentz RJ, Fiuzat M, Shaw LK, Farzaneh-Far A. C MOC, BorgesNeto S. Ischaemia change with revascularisation versus medical therapy in reduced ejection fraction. Open Heart 2015;2:e000284.

24. Iskandrian AE, Hage FG, Shaw LJ, Mahmarian JJ, Berman DS. Serial myocardial perfusion imaging: Defining a significant change and targeting management decisions. Jacc 2014;7:79-96.
25. El-Hajj S, AlJaroudi WA, Farag A, Bleich S, Manaoragada P, Iskandrian $\mathrm{AE}$, et al. Effect of changes in perfusion defect size during serial regadenoson myocardial perfusion imaging on cardiovascular outcomes in high-risk patients. J Nucl Cardiol 2016;23:101-12.

26. Xie JX, Winchester DE, Phillips LM, Hachamovitch R, Berman DS, Blankstein R, et al. The elusive role of myocardial perfusion imaging in stable ischemic heart disease: Is ISCHEMIA the answer? J Nucl Cardiol 2017. https://doi.org/10.1007/s12350017-0963-3. 